\title{
COMPORTAMENTO SAZONAL DA EXPORTAÇÃO BRASILEIRA DE CELULOSE PARA A CHINA ENTRE 1997 E 2012
}

\author{
Philipe Ricardo Casemiro Soares ${ }^{1}$, Marcos Vinícius Cardoso ${ }^{2}$, Elisangela Lobo Schirigatti ${ }^{3}$, \\ Alexandre Nascimento de Almeida ${ }^{4}$, João Carlos Garzel Leodoro da Silva ${ }^{5}$, Romano Timofeiczyk Junior ${ }^{5}$ \\ ${ }^{1}$ Universidade do Estado de Santa Catarina, Departamento de Engenharia Florestal, Lages, Santa Catarina, Brasil - \\ philipe.soares@udesc.br \\ ${ }^{2}$ STCP, Curitiba, Paraná, Brasil - mvcardoso@stcp.com.br \\ ${ }^{3}$ Universidade Tecnológica Federal do Paraná, Departamento de Desenho Industrial, Curitiba, Paraná, Brasil - \\ contatoelislobo@gmail.com \\ ${ }^{4}$ Universidade de Brasília, Planaltina, Distrito Federal, Brasil - alexalmeida @unb.br \\ ${ }^{5}$ Universidade Federal do Paraná, Departamento de Economia Rural e Extensão, Curitiba, Paraná, Brasil - \\ garzel@ufpr.br; romano@ufpr.br \\ Recebido para publicação: 12/08/2013 - Aceito para publicação: 21/01/2015
}

\begin{abstract}
Resumo
Este trabalho objetivou avaliar a sazonalidade do preço da celulose brasileira comercializada com a China como ferramenta para auxiliar na tomada de decisão sobre a comercialização do produto no mercado externo. Para isso, foram coletados, no Sistema ALICE-WEB, dados de quantidade e valores totais das exportações brasileiras de celulose para a China e, após deflacionamento, foram estimados os preços de venda do produto, para a determinação do índice sazonal para diferentes períodos entre 1997 e 2012. Os resultados mostraram que o preço do produto é instável durante o ano, no entanto tende a ser superior durante o segundo semestre, mais especificamente no terceiro trimestre. Essas informações indicam que as empresas devem fortalecer o comércio de celulose com a China nesses períodos, buscando mercados alternativos quando os preços estiverem mais baixos.

Palavras-chave: Sazonalidade; comércio internacional; pasta química de madeira; competitividade.
\end{abstract}

\begin{abstract}
Seasonal behavior of Brazilian pulp exports to China between 1997 and 2012. This study aimed to evaluate the seasonality of the price of Brazilian pulp traded with China as a tool to assist in decision making about commercialization of this product in external market. For this, data of quantity and total value from the Brazilian pulp exports to China were collected, in ALICE-WEB database, and after deflation, prices of product sales were estimated to determine the seasonal index for different periods between 1997 and 2012. The results showed that the price of the product is unstable during the year, but tends to be higher in the second semester, more specifically in the third trimester. This information indicates that companies should strengthen pulp trade pulp trade with China during these periods, seeking alternative markets when prices are lower.

Keywords: Seasonality; international trade; chemical wood pulp; competitiveness.
\end{abstract}

\section{INTRODUÇÃO}

O Brasil se destaca no mercado mundial de celulose, principalmente pela produtividade de suas florestas plantadas e pelos baixos custos de produção, comparativamente a outros países. Nesse segmento, o principal produto exportado pelo país é a pasta química de não coníferas (especificamente de Eucalyptus spp.) semibranqueada, que representou, em 2012, aproximadamente $92 \%$ das exportações totais de celulose, ou seja, US\$ 4,3 bilhões (MINISTÉRIO DO DESENVOLVIMENTO, INDÚSTRIA E COMÉRCIO EXTERIOR (MDIC), 2013).

Apesar de historicamente os Estados Unidos serem os maiores importadores da celulose produzida no Brasil, nos últimos anos a China se tornou o principal parceiro comercial do produto brasileiro, consumindo 33\% do que o país exportou até abril de 2013 (ASSOCIAÇÃO BRASILEIRA DE CELULOSE E PAPEL (BRACELPA), 2013). 
Mesmo com os aspectos favoráveis, o mercado internacional de celulose é altamente competitivo. Dessa forma, as empresas brasileiras do segmento atuam como tomadoras de preço (SEIFFERT; BACHA, 2007), o que implica baixo poder na definição dos preços, ficando assim mais expostos à instabilidade dessa variável.

Parte dessa instabilidade está relacionada aos efeitos cíclicos, seja pelo lado da oferta, seja da demanda ou por política macroeconômica, além de efeitos aleatórios, sendo que muitos desses fatores são sazonais (SANTANA; RODRIGUES JÚNIOR, 2000).

Dessa maneira, o conhecimento do comportamento sazonal do preço é importante na definição de estratégias visando a obtenção ou aumento da vantagem competitiva, não apenas pelo aumento da produtividade ou redução dos custos, mas também considerando aspectos de comercialização do produto.

No entanto, a realização de estudos globais de competitividade, apesar de importante, apresentam valores médios e por isso não representam com exatidão todas as relações comerciais de um país (CARDOSO et al., 2013). Dessa maneira, pesquisas de mercados específicos, em que as empresas efetivamente competem, são fundamentais para a elaboração de estratégias.

Nesse sentido, o comportamento sazonal no agronegócio, de maneira global e específica, vem sendo estudado em trabalhos publicados desde a década de 1960, como o de Pereira et al. (1963), que estudaram a variação sazonal de diversos produtos agrícolas para o estado de São Paulo.

Além dessa, destacam-se as pesquisas de Crocomo (1972) para produtos hortícolas, Barbosa et al. (1995) sobre preço de óleos vegetais, Bueno et al. (1999), Santana e Rodrigues Júnior (2000), Morgado et al. (2004) e Bengozi et al. (2007) no mercado de frutas, Margarido et al. (2003), que estudaram os preços dos alimentos na cidade de São Paulo, Zilli e Barcellos (2006) para o arroz, Lamounier (2007) sobre os preços do café brasileiro, Viana et al. (2010) e Marin et al. (2011), ambos avaliando o mercado de leite.

No entanto, no setor de base florestal, as pesquisas sobre o tema são incipientes, destacando-se os trabalhos de Cardoso et al. (2013), que estudaram o comportamento sazonal do preço da celulose brasileira no mercado norte-americano, Seiffert e Bacha (2007), que avaliaram o preço desse produto no mercado mundial, Cortez e Martin (1996), com a análise da sazonalidade da produção da seringueira, Perez e Bacha (2007), que estudaram o comportamento do preço da madeira serrada nos mercados paulista e paraense, e Matsushita (1993), que avaliou o padrão sazonal do comércio de madeira no Japão.

Observada a importância do tema e a necessidade de estudos nessa área, essa pesquisa teve como hipótese que o índice de preços da celulose brasileira comercializada com a China apresenta comportamento sazonal. Assim, objetivou-se analisar a sazonalidade do preço da pasta química de madeira de não coníferas semibranqueada, que o Brasil exportou para a China no período de 1997 a 2012, como suporte para a definição de estratégias e tomada de decisão das empresas do segmento.

\section{MATERIAL E MÉTODOS}

Considerando a grande participação na pauta de exportações brasileiras, selecionou-se para esta análise o produto "Pastas químicas de madeira de não conífera, à soda ou sulfato, semibranqueada", registrado pela Nomenclatura Comum do MERCOSUL (NCM) sob o código 4703.29.00 (MDIC, 2013).

Dados mensais sobre os valores e quantidades exportados desse produto para a China foram coletados no sistema ALICE-WEB, no período de janeiro de 1997 a dezembro de 2012, o que representa 192 observações.

$\mathrm{Na}$ sequência, esses valores foram deflacionados pelo Consumer Price Index (CPI) dos Estados Unidos, considerando dezembro de 2012 como o período-base. Após o deflacionamento, obteve-se o índice de preço unitário da celulose brasileira no mercado chinês, pela razão entre valor (US\$ FOB) e quantidade exportada, como apresentado na equação 1, indicada por Cardoso et al. (2013).

$$
\mathrm{P}_{\mathrm{u}}=\frac{\mathrm{R}_{\mathrm{b}}}{\mathrm{Q}}
$$

em que: $\mathrm{P}_{\mathrm{u}}=$ preço unitário do produto (US\$/t);

$\mathrm{R}_{\mathrm{b}}=$ receita bruta real (US\$);

$\mathrm{Q}=$ quantidade exportada $(\mathrm{t})$. 


\section{Análise de ciclos}

Essa etapa da pesquisa se baseia na definição de ciclos apresentada por Lamounier (2007) e Souza (1989), na qual ciclos, em séries temporais, podem ser considerados como movimentos de elevação e queda de uma variável. Tal variação ocorre em torno de um nível médio ou tendência, sem necessariamente apresentar comportamento periódico.

Assim, os índices de preço unitário do produto foram plotados em gráfico, permitindo a análise visual de sua variação, o que possibilitou a divisão do período avaliado em ciclos, a partir das quebras de série, decorrentes de queda abrupta do preço. Essas quebras seguem comportamento cíclico descrito por Levine et al. (2008), com oscilações repetidas ao longo de quatro fases, sendo elas: prosperidade (pico), recessão (contração), depressão (fundo) e crescimento (expansão).

\section{Dessazonalização e determinação do índice estacional de preços}

Os procedimentos adotados neste trabalho são embasados em Hoffmann (2006) e Santana e Rodrigues Júnior (2000). Tais autores afirmam que o preço de qualquer produto pode ser decomposto em três componentes, conforme representado na expressão 2 .

$$
P_{t}=P_{i j}=a+b_{t}+e_{j}+u_{t}
$$

em que: $\mathrm{P}_{\mathrm{t}}=$ preço unitário (US\$/t);

$P_{\mathrm{ij}}=$ preço em determinado ano (i) e mês (j);

$a+b_{t}=$ tendência linear, em que a e b são parâmetros;

$e_{j}=$ componente estacional, tal que ${ }_{j=1}^{12} e_{j}=0$;

$\mathrm{u}_{\mathrm{t}}=$ termo aleatório, com $\mathrm{E}\left(\mathrm{u}_{\mathrm{t}}\right)=0$.

De acordo com Levine et al. (2008) e Lamounier (2007), essa equação indica a existência de um componente estacional nos preços de produtos referente à sazonalidade, que pode ser definida como flutuações periódicas em intervalos de 12 meses, observadas em diversas variáveis, incluindo o preço de bens e serviços.

Verificado o comportamento sazonal, a análise de sazonalidade é uma ferramenta importante para as empresas exportadoras, incluindo as de celulose, por permitir o planejamento da produção e comercialização do produto no decorrer do ano, buscando aumentar a lucratividade e a competitividade (CARDOSO et al., 2013).

Para a determinação da variação sazonal dos preços de celulose de pasta química de não coníferas brasileira, comercializada com a China, inicialmente calculou-se o índice estacional para o período de agosto de 1997 a junho de 2010. Para tal, fez-se uso da equação 3, apresentada por Hoffmann (2006), permitindo assim observar a variação do preço da celulose, ao longo de todo o período de análise, em torno do seu valor médio.

$$
\mathrm{IE}_{\mathrm{t}}=\mathrm{D}_{\mathrm{ij}}=\frac{\mathrm{P}_{\mathrm{t}}}{\mathrm{G}_{\mathrm{t}}}
$$

em que: $\mathrm{IE}_{\mathrm{t}}$ e $\mathrm{D}_{\mathrm{ij}}=$ índice estacional;

$\mathrm{P}_{\mathrm{t}}=$ preço unitário $(\mathrm{US} \$ / \mathrm{t})$;

$\mathrm{G}_{\mathrm{t}}=$ média geométrica móvel dos preços.

Complementando os procedimentos para a avaliação da sazonalidade, determinou-se o índice sazonal do preço, que mostra a tendência de oscilação da variável, de acordo com a equação 4, apresentada por Hoffmann (2006).

$$
{ }_{j}=\frac{G_{j}}{C} 100
$$


em que: $\varepsilon_{\mathrm{j}}=$ índice sazonal;

$\mathrm{G}_{\mathrm{j}}=$ média geométrica dos preços do j-ésimo mês;

$\mathrm{C}=$ média geométrica dos índices estacionais.

Além disso, calculou-se o índice de irregularidade (equação 5). Conforme Hoffmann (2006), esse índice permite determinar os limites inferior e superior dos índices sazonais, respectivamente, pelo produto e razão entre os índices sazonal e de irregularidade.

$$
\mathrm{S}_{\mathrm{J}}=\operatorname{EXP}\left(\mathrm{s}_{\mathrm{j}}\right)
$$

em que: $S_{j}=$ índice de irregularidade;

$\mathrm{s}_{\mathrm{j}}=$ desvio padrão dos preços do j-ésimo mês;

Para a análise da sazonalidade dos preços, os dados foram reagrupados em subperíodos distintos, em função das quebras de série como definida na avaliação de ciclos, bem como foi também avaliada a série total para fins de comparação, como proposto por Cardoso et al. (2013). Quando a duração desses subperíodos não era múltipla de 12 meses, alguns deles, no final do intervalo, foram eliminados, para possibilitar o cálculo dos índices.

Apesar de Hoffmann (2006) apontar que, para a comparação da sazonalidade entre diferentes períodos, eles devem ter a mesma duração, essa recomendação não foi seguida, pois um dos objetivos foi realizar a comparação do padrão sazonal em cada ciclo encontrado. Como estes normalmente não possuem a mesma duração, essa recomendação foi flexibilizada, o que não interfere na qualidade dos resultados pretendidos.

\section{RESULTADOS E DISCUSSÃO}

\section{Avaliação de ciclos e comportamento dos preços}

A figura 1 apresenta a variação do preço unitário real da celulose fibra curta brasileira exportada para a China, bem como os três diferentes ciclos observados para o período de análise.

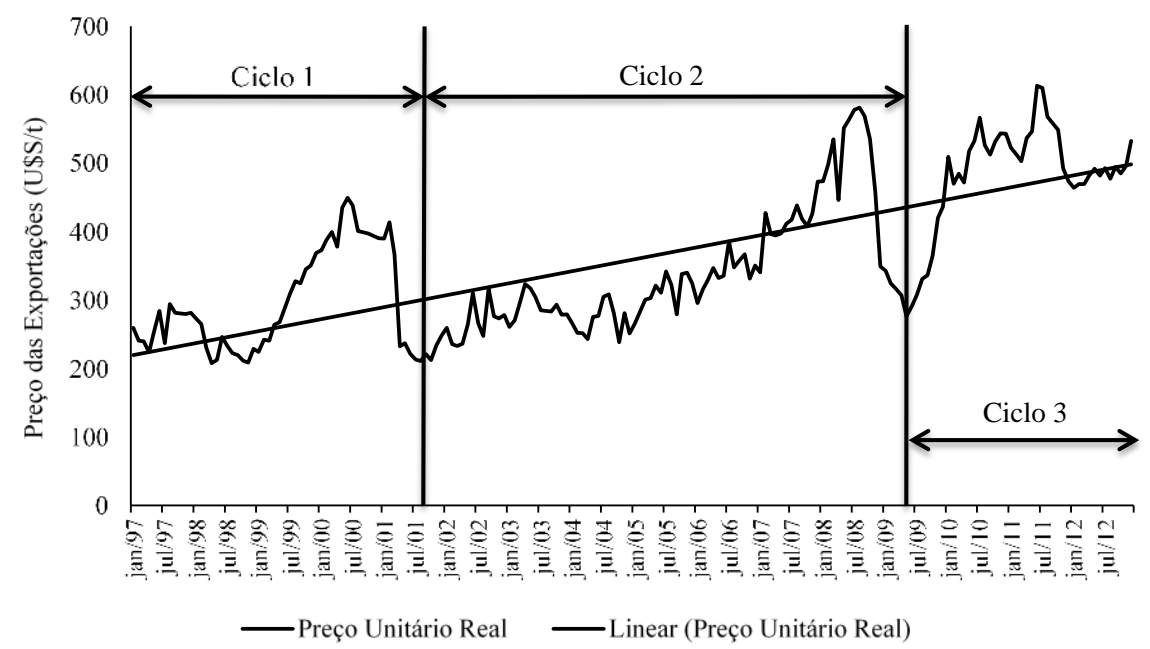

Figura 1. Variação do preço unitário da pasta química de madeira de não coníferas exportada para a China.

Figure 1. Variation of the unit prices of chemical pulp from hardwood exported to China.

Fonte: Elaborado pelos autores a partir de dados de MDIC (2013).

Observa-se, na figura 1, a instabilidade do valor pago pelos chineses na compra da celulose brasileira, com tendência de elevação nos preços dentro do intervalo de tempo avaliado, em taxa média de $6,6 \%$ ao ano. A elevação no preço da celulose no mercado chinês pode ser explicada, conforme Bacha 
(2012), pelo aumento da demanda do país pelo produto, especialmente a pasta química de não coníferas. Além disso, destaca-se a existência de três ciclos, caracterizados por longos períodos (superiores a três anos), com tendência à elevação nos preços, seguidos por queda abrupta.

O primeiro ciclo compreende o período entre janeiro de 1997 a agosto de 2001 (56 meses), o segundo entre setembro de 2001 e maio de 2009 (93 meses). Já o último ciclo, com 43 meses (junho de 2009 a dezembro de 2012), não finalizado até a ocasião da coleta de dados, tendendo a continuar em expansão, desde que eventos importantes não o encerrem, iniciando um novo ciclo.

Esse comportamento dos preços (número de ciclos e tendência) da celulose comercializada com a China foi diferente do encontrado por Cardoso et al. (2013), que avaliaram o comércio do produto brasileiro no mercado norte-americano. Nesse caso, os autores dividiram os valores das exportações foram divididos em quatro ciclos, para o período de janeiro de 2007 a dezembro de 2010, com tendência de longo prazo de redução dos preços.

Essa diferença, especialmente com relação à tendência, é observada pelos valores da celulose para os Estados Unidos no primeiro ciclo, quando o preço real do produto alcançou os mais elevados valores. Uma possível explicação para esse aumento, conforme dados apresentados pelo Banco Nacional de Desenvolvimento Econômico e Social (BNDES) (1999), é o fechamento de fábricas americanas de celulose, acarretando no aumento da demanda pelo produto brasileiro.

Para o mercado chinês, é observado, como característica geral dos ciclos, o aumento dos preços da celulose fibra curta brasileira, chegando a um patamar máximo e seguido de uma queda abrupta, comportamento relacionado à relação entre a demanda e a oferta do produto. Como no trabalho de Cardoso et al. (2013), não foi observado padrão cíclico com periodicidade bem definida, fato que dificulta as formulações de estratégias para a comercialização do produto com a China.

Esse comportamento cíclico sem periodicidade definida está de acordo com o descrito por Pizzol e Bacha (1998), em que o preço da celulose brasileira no mercado mundial apresenta ciclos com duração não periódica, caracterizando-se por intensa flutuação e imprevisibilidade de períodos de alta e baixa. Dessa maneira, esses autores sugerem que, para a obtenção de vantagem competitiva, as organizações devem investir em períodos de queda de preços, para que os resultados sejam colhidos em fases favoráveis.

Com relação aos fatores que geraram o encerramento dos ciclos, para o primeiro com final em agosto de 2001, as possíveis causas para a queda dos preços, de acordo com informações apresentadas por Klabin (2001) e Biazus et al. (2010), são a manutenção dos estoques de celulose elevados, aliada à queda da demanda mundial em função da instabilidade econômica na época. Esses resultados são semelhantes ao encontrado por Cardoso et al. (2013) para a exportação de pasta química para os Estados Unidos, indicando que a queda nos preços foi global, e não específica para alguns mercados.

Já o final do segundo ciclo, que coincide com o terceiro do estudo de Cardoso et al. (2013), foi resultado dos efeitos da crise mundial de 2008, que, de acordo com Barret (2011) e Vervloet e Garcia (2010), acarretou a redução da demanda e, consequentemente, dos preços. O último ciclo ainda não foi encerrado, sendo observado um período de queda no segundo semestre de 2011, em função de estoques elevados, recessões econômicas e taxa de câmbio (CELULOSEONLINE, 2011).

\section{Padrão de variação estacional}

Assim como nos resultados apresentados por Cardoso et al. (2013) para o mercado americano, também foi verificada grande variação no padrão de oscilação da pasta química de não coníferas brasileira comercializada com a China (Figura 2). A instabilidade de preços dificulta a definição de estratégias para as empresas do segmento.

A alta instabilidade é representada pela amplitude de variação do índice estacional, que foi de aproximadamente 49 , tendo os menores índices $(80,86)$ e, consequentemente, preço do produto, ocorrido em abril de 2001, e os maiores índices $(129,92)$ e preço no mês de fevereiro do mesmo ano. Esses valores ocorreram durante o primeiro ciclo e diferem do encontrado por Cardoso et al. (2013) para o mercado americano, em que o maior valor $(124,5)$ ocorreu em 2003 e o menor $(73,89)$ em 2004.

Apesar da maior amplitude, o primeiro período apresentou o segundo maior coeficiente de variação $(\mathrm{CV}=7,62 \%)$, ficando atrás do ciclo de número dois $(7,96 \%)$. Já a menor variação foi observada no terceiro período, com CV de $6,17 \%$. Comparativamente ao mercado americano, conforme apresentado por Cardoso et al. (2013), o índice estacional para celulose exportada para a China sofreu maior variação, indicando maior instabilidade de preços. 


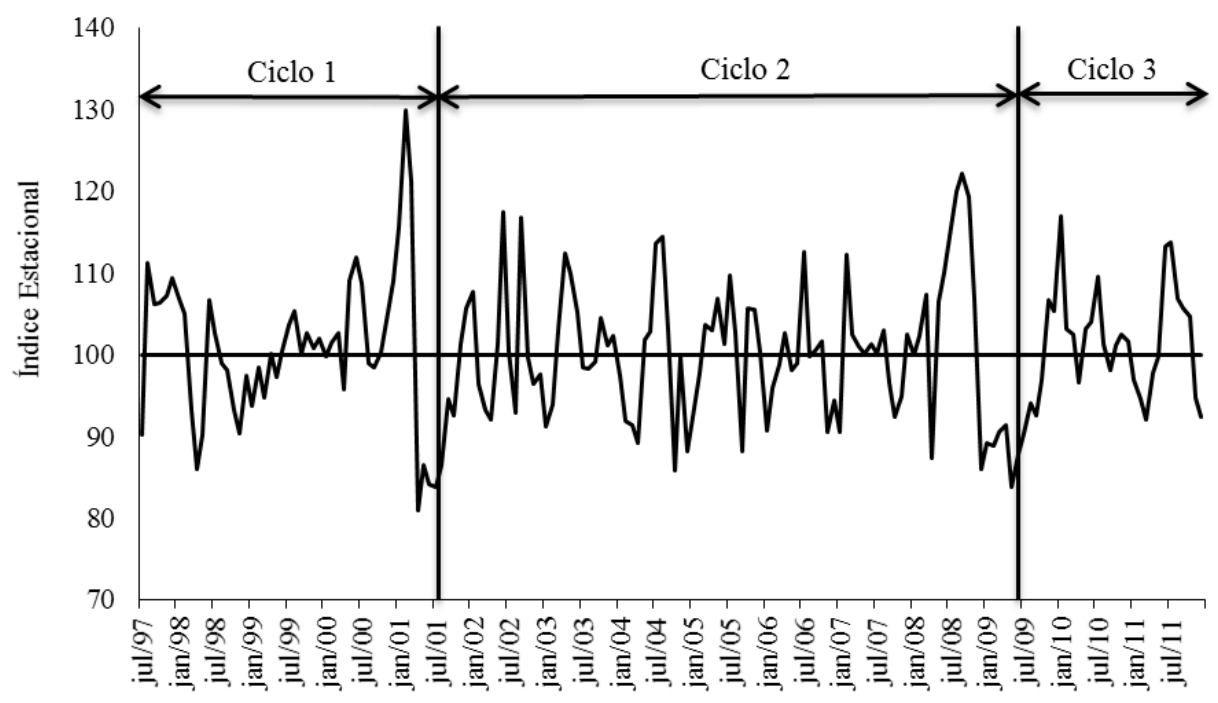

Figura 2. Índice estacional do preço da celulose de não coníferas exportadas para a China. Figure 2. Seasonal index for prices of chemical pulp from hardwood exported to China. Fonte: Elaborado pelos autores a partir de dados de MDIC (2013).

Essas diferenças dos resultados dos dois estudos indicam que as estratégias a serem seguidas para o comércio da pasta química de não coníferas com o mercado chinês devem ser diferentes daquelas adotadas para a venda para os Estados Unidos, dificultando ainda mais a gestão das empresas do segmento de celulose e papel brasileiro.

\section{Padrão da variação sazonal}

A figura 3 apresenta os índices sazonais (IS), bem como seu limite superior (IS+) e limite inferior (IS-) para quatro períodos: período total de análise (P1 - janeiro de 1997 a dezembro de 2012), Ciclo 1 (P2 - janeiro de 1997 a agosto de 2001), Ciclo 2 (P3 - setembro de 2001 a maio de 2009) e Ciclo 3 (P4 - junho de 2009 a dezembro de 2012).

Esses dados também podem ser visualizados na tabela 1 .

Analisando-se os resultados (Figura 3 e Tabela 1), todos os períodos apresentaram comportamento semelhante quanto ao IS médio para o ano (aproximadamente 100,05), sendo pouco menor para P1 (100,02), período que também apresentou menor amplitude de dados (7,7). Além disso, é possível observar que os maiores índices sazonais e, consequentemente, preços de comercialização da celulose no mercado chinês foram: 103,1 no mês de julho para o período total (P1), 106,5 em fevereiro para P2, 106,2 para P3 e 109,9 para P4, ambos registrados no mês de julho.

Dessa maneira, pode-se dizer que o mês de julho é o melhor para a comercialização de celulose com a China, apresentando preços mais elevados. Além disso, em termos médios, os maiores preços se concentraram no segundo semestre do ano, como também observado por Cardoso et al. (2013) para o mercado norte-americano. No entanto, esses resultados diferem do trabalho de Seiffert e Bacha (2007), em que os valores superiores foram registrados no início do ano. Essa diferença pode ser função da abrangência do trabalho, tanto para o tempo quanto para os mercados analisados.

Considerando-se os dados trimestrais, uma análise de longo prazo (P1) indica que o terceiro trimestre foi o que apresentou os maiores preços para a celulose brasileira no mercado chinês, seguido pelo quarto, primeiro e segundo trimestres. Esse resultado foi diferente do descrito por José Penido e Antonio Maciel Neto, presidentes, na época, respectivamente, do conselho de administração da Fibria e da Suzano Papel e Celulose, e apresentado por Marcondes (2010), em que os preços da celulose são baixos no primeiro trimestre, crescentes no segundo, arrefecidos no terceiro e intensos no quarto trimestre do ano.

A análise de preços feita pelos administradores é global, considerando todos os parceiros comerciais do Brasil. Quando comparado a estudos em mercados específicos, os resultados podem ser próximos ao comportamento por eles descrito, como no estudo de Cardoso et al. (2013) para os Estados Unidos, ou diferentes, como os observados neste trabalho para o mercado chinês. 

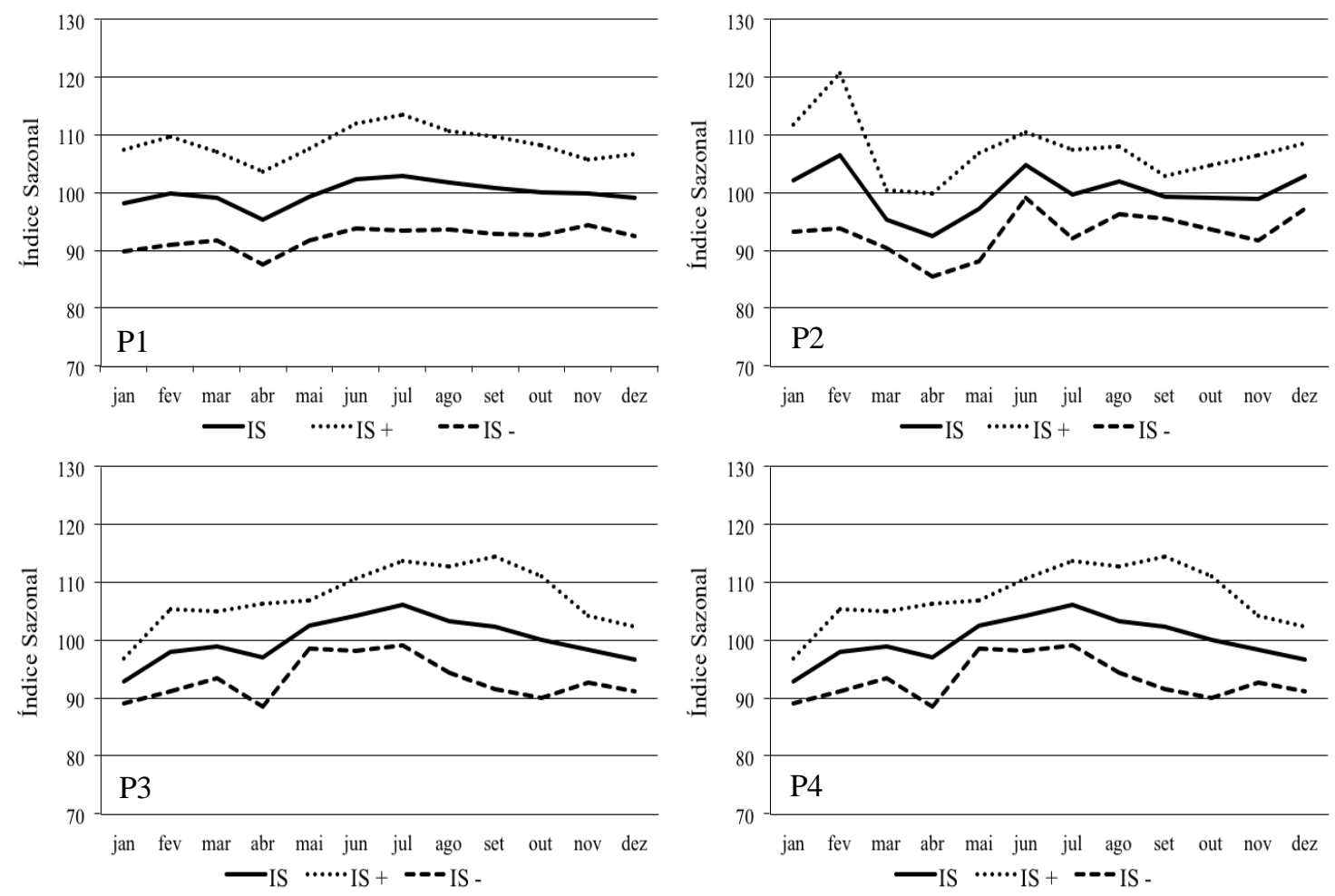

Figura 3. Variação sazonal do preço da celulose de não coníferas exportada para a China nos períodos de análise.

Figure 3. Seasonal variation of the prices of chemical pulp from hardwood exported to China in the periods of analysis.

Fonte: Elaborado pelos autores a partir de dados de MDIC (2013).

Tabela 1. Índice sazonal do preço e seus limites para celulose de não coníferas exportada para a China.

Table 1. Seasonal index for prices and its limits of chemical pulp from hardwood exported to China.

\begin{tabular}{|c|c|c|c|c|c|c|c|c|c|c|c|c|}
\hline \multirow{2}{*}{ Mês } & \multicolumn{3}{|c|}{ P1 } & \multicolumn{3}{|c|}{$\mathbf{P 2}$} & \multicolumn{3}{|c|}{ P3 } & \multicolumn{3}{|c|}{ P4 } \\
\hline & IS & IS+ & IS- & IS & IS+ & IS- & IS & IS+ & IS- & IS & IS+ & IS- \\
\hline Jan & 98,3 & 107,5 & 90,0 & 102,3 & 112,0 & 93,4 & 92,9 & 96,9 & 89,1 & 99,9 & 113,2 & 88,2 \\
\hline Fev & 100,0 & 109,7 & 91,1 & 106,5 & 120,8 & 93,9 & 98,0 & 105,4 & 91,1 & 96,0 & 100,8 & 91,4 \\
\hline Mar & 99,2 & 107,2 & 91,8 & 95,4 & 100,5 & 90,6 & 99,0 & 105,0 & 93,4 & 95,3 & 100,6 & 90,3 \\
\hline Abr & 95,4 & 103,8 & 87,6 & 92,5 & 100,0 & 85,5 & 97,1 & 106,4 & 88,6 & 96,5 & 98,1 & 94,9 \\
\hline Mai & 99,4 & 107,7 & 91,8 & 97,2 & 107,0 & 88,3 & 102,6 & 106,9 & 98,5 & 100,1 & 101,8 & 98,5 \\
\hline Jun & 102,6 & 112,0 & 93,9 & 104,7 & 110,6 & 99,2 & 104,3 & 110,7 & 98,2 & 103,8 & 110,8 & 97,3 \\
\hline Jul & 103,1 & 113,6 & 93,5 & 99,7 & 107,7 & 92,3 & 106,2 & 113,7 & 99,1 & 109,9 & 112,9 & 107,0 \\
\hline Ago & 101,9 & 110,7 & 93,8 & 102,1 & 108,1 & 96,4 & 103,2 & 112,9 & 94,4 & 102,4 & 106,4 & 98,6 \\
\hline Set & 101,0 & 109,7 & 92,9 & 99,3 & 103,0 & 95,7 & 102,4 & 114,5 & 91,5 & 100,3 & 105,8 & 95,1 \\
\hline Out & 100,1 & 108,2 & 92,7 & 99,2 & 104,9 & 93,8 & 100,0 & 111,1 & 90,1 & 101,3 & 103,8 & 98,9 \\
\hline Nov & 100,0 & 105,9 & 94,4 & 99,0 & 106,7 & 91,9 & 98,4 & 104,3 & 92,8 & 97,1 & 102,7 & 91,8 \\
\hline Dez & 99,3 & 106,7 & 92,5 & 102,9 & 108,8 & 97,3 & 96,6 & 102,4 & 91,2 & 98,1 & 105,0 & 91,7 \\
\hline
\end{tabular}

Fonte: Elaborado pelos autores a partir de dados de MDIC (2013).

No entanto, durante a formulação de estratégias, também é importante a avaliação dos movimentos de curto prazo. No caso da comercialização da celulose com a China, apesar do destaque para o terceiro trimestre, a movimentação dos preços sofreu grande variação em cada ciclo analisado (P2, P3 e P4). Esse fato mostra a importância da realização de análises de curto prazo pelas empresas para a definição das estratégias a serem seguidas.

FLORESTA, Curitiba, PR, v. 45, n. 2, p. 251 - 260, abr. / jun. 2015.

Soares, P. R. C. et al.

ISSN eletrônico 1982-4688 / ISSN impresso 0015-3826 
Já com relação aos menores valores de IS e, consequentemente, preços da celulose comercializada no mercado chinês, houve concentração no primeiro semestre do ano, sendo: P1) 95,4 em abril, P2) 92,5 em abril, P3) 92,9 em janeiro e P4) 95,3 em março.

Os limites superior (IS+) e inferior (IS-), apresentados na figura 3, apresentam, para cada mês, o intervalo de dispersão dos índices sazonais do preço da celulose brasileira comercializada com a China. De maneira geral e em termos médios, a maior variação é observada no primeiro semestre do ano, o mesmo que apresentou menores preços, indicando maior atenção para a definição de estratégias nesse período.

Já na análise dos períodos, observou-se relação direta da dispersão média com a duração do ciclo. Dessa maneira, a menor dispersão ocorreu no ciclo 3 (P4), mais curto e ainda não encerrado, e a maior no longo prazo (período total - P1).

Com relação aos limites apresentados na figura 3, é possível notar diferenças nos resultados de curto e longo prazos. No curto prazo (P2, P3 e P4), os limites sofrem variações durante o ano e na comparação dos períodos, enquanto que no longo prazo (P1) não é observada grande oscilação de um mês para outro.

Os resultados observados nesta avaliação da sazonalidade do preço da celulose brasileira comercializada com a China podem auxiliar as empresas do segmento na tomada de decisão. O fato de os maiores preços estarem concentrados no segundo semestre e terceiro trimestre indica que esforços de venda da pasta química de não coníferas no mercado chinês devem ser concentrados, sempre que possível, nesses períodos.

Além disso, as diferenças nos resultados encontrados para aqueles apresentados por Cardoso et al. (2013) mostram a complexidade para a definição de estratégias nas organizações que atuam tanto no mercado norte-americano como no chinês. Nesse caso, é aconselhável o desenvolvimento de estratégias específicas para cada mercado.

\section{CONCLUSÕES}

- A partir dos resultados obtidos, pode-se concluir que o preço da celulose brasileira comercializada com a China possui comportamento cíclico sem padrão definido. Além disso, foram observadas variações no índice sazonal, com maiores valores observados no segundo semestre. Assim, pode-se dizer que o preço da celulose exportada para a China é maior nesse período.

- Esses resultados indicam a importância da realização de estudos sobre sazonalidade de preço como base para a definição de estratégias específicas de venda do produto para diferentes parceiros comerciais. Assim, no caso da China, os resultados indicam que as empresas devem concentrar esforços para a comercialização da celulose no segundo semestre, buscando mercados alternativos em outras épocas do ano.

- No entanto, apesar de se mostrar importante, o estudo de sazonalidade de preço não deve ser utilizado como a única ferramenta para a definição de estratégias, sendo necessário maior número de informações que auxiliem na tomada de decisão, como análise de oferta e demanda.

\section{REFERÊNCIAS}

ASSOCIAÇÃO BRASILEIRA DE CELULOSE E PAPEL (BRACELPA). Balança Comercial: Maio de 2013. 2013. Disponível em: 〈http://www.bracelpa.org.br/bra2/sites/default/files/conjuntura/CB-054.pdf>. Acesso em: 06/08/2013.

BACHA, C. J. C. Terminou o ciclo de queda de preços da celulose? O Papel, n. 4, p. 21 - 24, 2012.

BANCO NACIONAL DE DESENVOLVIMENTO ECONÔMICO E SOCIAL (BNDES). Papel e Celulose - comércio exterior. 1999. Disponível em: <http://www.bndes.gov.br/SiteBNDES/export/sites/ default/bndes_pt/Galerias/Arquivos/conhecimento/setorial/is_g1_18.pdf >. Acesso em: 06/08/2013.

BARBOSA, M. Z.; ROCHA, M. B.; FREITAS, S. L. de. Sazonalidade dos preços dos principais óleos vegetais no mercado internacional. Informações Econômicas, São Paulo, v. 25, n. 3, p. 9 - 18, 1995. 
BARRET, R. G. Operações de hedge cambial em empresas não financeiras: um estudo de caso das Empresas Aracruz Celulose e Sadia. 38 f. Dissertação (Mestrado em Administração) - Fundação Getúlio Vargas, Rio de Janeiro, 2011.

BENGOZI, F. J.; SAMPAIO, A. C.; GUTIERREZ, A. D. S.; RODRIGUES, V. M.; PALLAMIN, M. L. Análise do mercado de abacaxi comercializado na CEAGESP, São Paulo. Revista Brasileira de Fruticultura, Jaboticabal, v. 29, n. 3, p. 494 - 499, 2007.

BIAZUS, A.; HORA, A. B. da; LEITE, B. G. P. Panorama de mercado: celulose. BNDES Setorial, Brasília, v. 32, p. 311 - 370, 2010.

BUENO, C. R.; REIS, R. P.; SOUZA, M. de. Estudo mercadológico da sazonalidade de frutos cítricos ofertados no município de Lavras, MG. Ciência e Agrotecnologia, Lavras, v. 23, n. 4, p. 813 - 824, 1999.

CARDOSO, M. V.; SOARES, P. R. C.; SILVA. J. C. G. L. da; TIMOFEICZYK JÚNIOR, R. Estudo da sazonalidade do preço da celulose brasileira no mercado dos Estados Unidos em períodos cíclicos como apoio a estratégias empresariais. Scientia Forestalis, Piracicaba, v. 41, n. 97, p. 47 - 55, 2013.

CELULOSEONLINE. Preço da celulose mantém tendência de queda nos mercados internacionais. 2011. Disponível em: <http://www.celuloseonline.com.br/noticias/Preo+da+celulose+mantm+tendncia+ de+queda+nos+mercados+internacionais $>$. Acesso em: 10/07/2013.

CORTEZ, J. V.; MARTIN, N. B. A sazonalidade da produção da seringueira e a política brasileira de contingenciamento da importação de borracha natural. Informações econômicas, São Paulo, v. 26, n. 7, p. $53-71,1996$.

CROCOMO, C. R. Variação estacional dos preços de produtos hortícolas no estado de São Paulo no período 1964-71. Piracicaba: USP/ESALQ, 1972.93 p.

HOFFMANN, R. Estatística para economistas. São Paulo: Thomson, 2006. 432 p.

KLABIN. Relatório anual 2001. 2001. Disponível em: <http://www.klabin.com.br/imagens/investidor/ relatorio-anual/2001_annual_report_03082010031100.pdf>. Acesso em: 10/07/2013.

LAMOUNIER, W. M. Tendência, ciclos e sazonalidade nos preços spot do café brasileiro na NYBOT. Gestão \& Produção, São Carlos, v. 14, n. 1, p. 13 - 23, 2007.

LEVINE, D. M.; STEPHAN, D. F.; KREHBIEL, T. C.; BERENSON, M. L. Estatística: teoria e aplicações. Rio de Janeiro: LTC, 2008. 752 p.

MARCONDES, C. Preços da celulose seguem em alta até o fim de 2010. O Globo, Rio de Janeiro, 07 abr. 2010. Disponível em: <http://oglobo.globo.com/economia/mat/2010/04/07/precos-da-celuloseseguem-em-alta-ate-fim-de-2010-916275221.asp>. Acesso em: 11/07/2013.

MARGARIDO, M. A.; BUENO, C. R. F.; MATINS, V. A. Sazonalidade da cesta de mercado paulistana pós-plano real. Informações Econômicas, São Paulo, v. 33, n. 12, p. 41 - 50, 2003.

MARIN, S. R.; CAVALHEIRO, A. G.; ANSCHAU, D. Sazonalidade do preço do leite no Rio Grande do Sul. Ciência Rural, Santa Maria, v. 42, n. 2, p. 361 - 364, 2011.

MATSUSHITA, K. The seasonal fluctuation of the products price II: the relationship between price indicator and quantitative indicator. Memoirs of the Faculty of Agriculture - Kagoshima University, Kagoshima, v. 29, p. 121 - 133, 1993.

MINISTÉRIO DO DESENVOLVIMENTO, INDÚSTRIA E COMÉRCIO EXTERIOR (MDIC). Sistema de análise das informações de comércio exterior. AliceWeb: banco de dados sobre comércio exterior do MDIC. Disponível em: <http://aliceweb2.mdic.gov.br>. Acesso em: 25/07/2013.

MORGADO, I. F.; AQUINO, C. A. P.; TERRA, D. C. T. Aspectos econômicos da cultura do abacaxi: sazonalidade de preços no estado do Rio de Janeiro. Revista Brasileira de Fruticultura, Jaboticabal, v. 26, n. 1, p. $44-47,2004$.

FLORESTA, Curitiba, PR, v. 45, n. 2, p. 251 - 260, abr. / jun. 2015. 
PEREIRA, I. F.; JUNQUEIRA, P. C.; CAMARGO, M. N. Variação estacional dos preços agrícolas no estado de São Paulo. Agricultura em São Paulo, São Paulo, v. 10, n. 4, p. 3 - 66, 1963.

PEREZ, P. L.; BACHA, C. J. C. Comercialização e comportamento dos preços da madeira serrada nos estados de São Paulo e Pará. Revista de Economia Agrícola, São Paulo, v. 54, n. 2, p. 103 - 119, 2007.

PIZZOL, S. J. S.; BACHA, C. J. C. Comportamento dos preços recebidos pelo Brasil para celulose exportada. Preços Agrícolas, Piracicaba, v. 12, n. 135, p. 8 - 9, 1998.

SANTANA, A. C.; RODRIGUES JÚNIOR, H. Análise da sazonalidade de preços das frutas comercializadas na Ceasa de Belém, no período de 1990 a 1998. Movendo Ideias, Belém, v. 5, n. 8, p. 22 $-34,2000$.

SEIFFERT, M. O.; BACHA, C. J. C. Análise da comercialização interna e externa da celulose brasileira, 45, 2007. In: CONGRESSO DA SOCIEDADE BRASILEIRA DE ECONOMIA, Administração e Sociologia Rural. Londrina, 2007, Anais... Londrina, 2007, p. 1 - 21.

SOUZA, R. C. Modelos estruturais para a previsão de séries temporais: abordagens clássica e bayesiana. Rio de Janeiro: Editora IMPA, 1989. 171 p.

VIANA, J. G. A.; ZEN, B.; KARLEC, F.; SOUZA, R. S. de. Comportamento dos preços históricos do leite no Rio Grande do Sul, Brasil. Ciência e Agrotecnologia, Lavras, v. 34, n. 2, p. 451 - 460, 2010.

VERVLOET, W.; GARCIA, M. Empresas exportadoras brasileiras e a crise - Incentivo perverso das reservas internacionais: o caso das empresas exportadoras brasileiras. Revista Brasileira de Comércio Exterior, Rio de Janeiro, v. 24, n. 102, p. 67 - 82, 2010.

ZILLI, J. B.; BARCELLOS, G. M. Padrão de variação estacional dos preços do arroz no estado do Rio Grande do Sul. Informações Econômicas, São Paulo, v. 36, n. 3, p. 7 - 17, 2006. 